\title{
POLÍTICAS CULTURAIS \\ E MIGRAÇÕES
}

José Roberto Severino

jseverino@ufba.br

Conceitos como democracia, quando observados sob o viés histórico, apresentam tantas configurações quantos forem às situações analisadas. A variedade de situações que cada análise pode comportar cabe a outros conceitos caros a todos nós, como nação, fronteira, cidadania, comunidade, território, migração. Sendo conceito, mas sendo também fato humano, configura-se entre práticas e representações do estar junto. E este é sempre um processo de deslocamento de percepções e de superação de estereótipos.

As experiências de quem vive em movimento sobre o território oferecem perspectivas amplas demais para serem sempre as mesmas. Demonstram que o significado da migração é histórico, ou seja, muda no tempo e no espaço. Migrações em escala regional ou local - aquelas que dizem respeito a uma dinâmica sazonal específica, ou às intempéries da natureza inclemente, ou ainda por lutas fratricidas pelo poder - podem ser encontradas ao longo da 
história contemporânea como uma das características da modernidade. De forma impressionante, foram aceleradas ao longo do breve século XX. As implicações deste ir e vir humano pelo planeta gerou também necessidades cada vez mais prementes: quem emigra, deixa o território, mas porta costumes, hábitos, cultura. Nesta perspectiva, cada vez mais verdadeira no tempo presente, as populações em fluxo são alvo de políticas culturais. Este foi o tema escolhido para esta reflexão.

\section{Migrar/emigrar/imigrar}

De início já emergem as questões referentes ao recorte escolhido. Migrar, ato de deslocar-se de seu lugar para outro. A origem territorial, linguística, religiosa e étnica dos indivíduos, define-se em símbolos, ritos e códigos que não estão necessariamente fora de uma comunidade nacional. O nacional, mesmo como invenção partilhada coletivamente de forma mais intensa na modernidade, pode abarcar variadas escalas e configurações.

Nos rastros dos movimentos nacionais, percebe-se a produção de identidades para grupos estáveis do lugar, a partir de noções de comunidade e nação, recorrendo a atavismos partilhados. A grande imigração é irmã siamesa da nação moderna, sendo ambas, filhas do capitalismo internacional do século XIX. Claro que poderíamos dar como o início de um movimento migratório moderno, aquilo que pode ser observado um pouco antes na Espanha do século XVI em direção à América. Aquele fenômeno produziu um efeito profundo nas representações de mundo à época. $\mathrm{O}$ traumático encontro de sociedades naquilo que Todorov chamou de A conquista da América (2001), promoveu o deslocamento das formas de vida das sociedades europeias, através da catequese e 
da construção de igrejas, templos da submissão que promoveram uma profunda ressignificação nas sociedades americanas, transformações que também ocorreram na Europa. Muitos europeus passaram a projetar um movimento rumo ao país da Cocagna. ${ }^{1}$ Migrar realizaria isso.

Convém, para melhor compreender o fenômeno no período contemporâneo, lembrar que alguns movimentos migratórios e alguns circuitos migratórios são mais antigos, mas nem sempre menos traumáticos. Beduínos no deserto do Magreb, ciganos em Portugal, trabalhadores vênetos na Hungria, trabalhadoras rurais trentinas no Vêneto.

Nos estudos sobre migração, a trajetória do próprio conceito em países como a Itália e os Estados Unidos demonstra a preocupação em facetas diferentes. Neste último, por ser um dos destinos da grande imigração europeia do século XIX, uma nação feita da mão imigrante, há uma sociologia da imigração. Na Itália, a historiografia demonstra a península como fruto de encontros que remontam a tempos muito remotos. Desde a última glaciação, ${ }^{2}$ quando a sedentarização começou a produzir as primeiras vilas de povos vindos de fluxos migratórios na grande bacia do Mediterrâneo. Ou da Fundação de Roma à chegada dos Etruscos, ou ainda mais tarde os povos germânicos, a península é entendida como um lugar de encontro de povos. A sangria de aldeias italianas para a América, também vai ser exaustivamente analisada pelos sociólogos e historiadores da imigração. A tentativa de uma revisão bibliográfica sobre o tema não caberia nestas páginas, a tempo, e as lacunas se mostram óbvias, já que se emigra em todos os continentes e há muito tempo. Na verdade, a migração é um tema que exige a reflexão sobre o problema da ação de emigrar conexa ao de imigrar. 
Para pensar a nação na atualidade, convém partir da noção que define o migrante sempre como um outro, um estranho a ser observado. Para pensadores como Voltaire e Rousseau, falar de defesas incontestes do direito de ir e vir como base da própria evolução da civilização. Enquanto ideia e princípio, essas noções eram exceções à época deles. O pensamento chamado Iluminista, baseado em princípios universalizantes, dava um tom para a ideia de lealdade e pertencimento cidadão. Ao mesmo tempo, tal princípio induz ao sentido amplamente difundido ao longo do século XIX e defendido pelo pensamento crítico que é o internacionalismo apresentado por Anderson (2005). O princípio da universalidade dos direitos e o exercício da liberdade através da circulação de pessoas e de ideias. Na Idade Média e por boa parte da Idade Moderna, os laços de parentesco produziam o efeito de fixidez. As relações sociais eram experiências que estavam ligadas à terra. As pessoas individualmente valiam menos do que com as suas famílias, em suas aldeias, nas suas irmandades. Todos os laços eram definidos a partir da comunidade cristã, produzida na tradição e na oralidade. Na modernidade passam a vigorar outras possibilidades. Assim, tomam relevo noções como soberania e individualidade.

Da mesma maneira que se individualizavam sujeitos, desenhavam-se outros contornos, comunidades individuais, nações. Com vistas a esta perspectiva, cabe lembrar das calorosas discussões sobre soberania, movimentos humanos e território. As definições dos limites disso podem ser encontradas no esforço para contar as hordas migratórias de camponeses ao longo de muitos braços perdidos por proprietários de terras ao longo dos séculos XVIII e XIX. A perda de mão de obra tanto quanto a de ocupantes do espaço nacional, tão caros à ideia de soberania, vão pautar parte das políticas nos séculos citados. Some-se a isso o fato de que surgia 
no final do século XVIII o sentido de nação e de nacionalismo no processo de transformação pela qual passava a indústria e a tecnologia. Para a nascente classe industriosa o estado nacional era imprescindível. Em resumo, controlar o movimento da população no território passa a ser imprescindível. (HOBSBAWM, 1991)

As nações coloniais, os impérios coloniais melhor dizendo, são outros produtos dessa era moderna. Talvez pela sua intensidade e extensão, seja também o centro de uma das questões sobre a migração contemporânea. É muito difícil falar de França sem tocar no Magreb. A Itália em relação à Tunísia, à Líbia ou a Marrocos. Alemanha e Turquia. Inglaterra e Jamaica. Bélgica e Congo. A atual posição dos países europeus em termos de qualidade de vida e oferta de empregos impele a novas leis sobre imigração. Nunca o mundo esteve tão interdependente. Até nações que sempre foram acolhedoras como os EUA e o Brasil incorporam tais ações.

Já naqueles tempos, fora os migrantes clássicos - na colheita sazonal em determinadas regiões, no preparo da terra, na engorda do gado - eram os ciganos que circulavam errantes pelo território. Leis rigorosas regulavam os seus movimentos. Mas a partir no século XIX, a confluência de alguns fatores faz emergir as condições de possibilidade de um fenômeno de maior monta: a imigração em massa. Irlandeses e o fluxo de famintos pela Europa e depois pela América vão fazer dos Estados Unidos o lugar da grande festa de São Patrício (mais do que na Irlanda atual). O lugar da cultura na vida dos descendentes de imigrantes permite seguir com a reflexão de Hall (1997), acerca da "centralidade da cultura". O autor, no mesmo caminho de Benko (1996), nos sugere para uma reflexão que confere à expressão cultura o lugar de campo epistemológico, e que não se permite mais que se analise a vida local deslocada de uma relação com o global. ${ }^{3}$ Assim como também, não se podem 
analisar os sujeitos sociais fora dessa complexa relação cultural que, a cada instante, interpela o sujeito, o subjetiva, exercendo poder sobre o corpo e a mente, podendo ser observada em "nossas ações, instituições, rituais e práticas”. (HALL, 1997, p. 22) $A$ "centralidade da cultura" para analisar as relações sociais se localiza no fato de que "toda prática social depende e tem relação com o significado" e nas práticas sociais há sempre relação de poder, de disputa, de forças para a produção e legitimação "do" significado. Assim, a cultura pode ser modelada, controlada e regulada, governando muitas ações e práticas sociais. Nessa sequência, os artefatos culturais ligados a práticas culturais eleitas, reinventadas ou herdados, tornam-se mais presentes e tendem a produzir, de forma mais acentuada, um significativo poder sobre as representações e práticas sociais locais.

É na modernidade que a estado-nação e seus imperativos categóricos derivados do nacionalismo irão se impor: fronteiras, passaportes, controle da população, balizas nacionais e alienígenas. $\mathrm{Na}$ verdade, o compasso disso é acelerado pelos meios de transportes cada vez mais eficientes, meios de comunicação cada vez mais sofisticados e baratos. Ao nos debruçarmos sobre o presente vamos encontrar a possibilidade do exercício das liberdades plenamente vivenciada por indivíduos emigrados em países que adotaram como seu. Este fato é fruto de inúmeras disputas de ordem filosófica dos séculos XVIII ao XIX, por exemplo, e podem hoje ser vivenciados como direito em muitos lugares. Evidentemente, nem sempre se dá desta forma. O Brasil, e toda a América, principalmente ao longo do século XIX, estiveram no destino dos fluxos migratórios [...] Regiões inteiras na Irlanda, Prússia e Itália (para citar os maiores fluxos) promoveram o redesenho da paisagem econômica e cultural da virada do século. ${ }^{4}$ Os trabalhos mais contemporâneos vêm se debruçando sobre as migrações de "retorno", principalmente entre estudio- 
sos europeus a preocupação é entender os mecanismos de pertencimento e ambientes cada vez mais marcados pelos encontros culturais. (FURTER; HEAD-KÖNIG; LORENZETTI, 2009)

Cabe lembrar que estudos na história ou sociologia da migração ${ }^{5}$ e suas implicações na cultura ${ }^{6}$ correspondem a uma guinada epistemológica recente. Em geral as análises se detinham sobre as condições de trabalho e as difíceis relações que se estabeleciam com os grupos em condições, muitas vezes, de clandestinidade. Mesmo com um longo percurso feito em países de imigração, como o Brasil, ${ }^{7}$ as pesquisas das relações culturais entre nacionais e imigrantes vêm se afirmando nos últimos anos.

\section{Políticas culturais e (i)migrantes: algumas observações contemporâneas}

Após 11 de setembro de 2001 passamos todos a viver o medo expandido, ${ }^{8}$ fruto da superprodução do fato, capaz de nos dizer que o mundo não seria mais o mesmo dali em diante. $\mathrm{O}$ simples ato de viajar passou a ser encarado como uma questão de segurança nacional. A maquinaria de Estado voltou aos poucos ao seu papel clássico de salvaguarda dos interesses nacionais. Segurança emerge como um imperativo categórico das políticas no milênio que se inicia. E os velhos discursos sobre os cuidados em torno da comunidade nacional justificaram as construções de novos muros no Oriente Médio, na fronteira do Rio Grande que separa México e Estados Unidos, no maior controle da imigração nos países europeus, mesmo com diferenças, observadas na Itália, Espanha, Grécia, Portugal, Grã-Bretanha, e França. 
A literatura e o cinema estão cheios de narrativas que nos dizem da produção desses medos do outro. Uma questão como o medo generalizado, parece atuar no equilíbrio entre a dose de liberdade e de segurança que cada sociedade delega às suas estruturas de proteção. Tal qual na Janela de Overton ${ }^{9}$ somos impulsionados para um novo medo sobre o outro. E também para a pergunta sobre liberdade e segurança. Para Isaiah Berlin (2009) existem dois tipos de liberdade: a negativa e a positiva. A definição de liberdade negativa é quando, ao invés de nos perguntarmos "por quem devemos ser governados", perguntamos "até onde devemos ser governados".

Isto tudo para dizer que migrar continua difícil, assim como transitar pelas fronteiras, que além de mais restritivo, têm sonegado direitos básicos de todos nós. Direitos definidos pela Unesco como fruto de conquistas ocidentais configuradas por lutas históricas. Determinações que exigem compromissos dos países signatários. ${ }^{10}$ Exemplo disso é o que ocorre após a eleição de George W. Bush em 2000, que prometia uma mudança na política de imigração nos EUA. Após trinta e cinco anos das últimas alterações importantes no sistema de imigração dos EUA, o presidente republicano parecia ver a imigração como maneira de oferecer benefícios importantes para a economia dos EUA. Estavam sendo organizados programas de grande escala para trabalho temporário, com foco na crescente população hispânica que eram, além de tudo, eleitores importantes. Foram inúmeras viagens e reuniões em nove meses com o presidente recém-eleito do México, Vicente Fox. As negociações sobre as questões migratórias com o México entraram em colapso após os ataques terroristas contra os Estados Unidos em Setembro de 2001.

No período após 11 de setembro, o Congresso dos Estados Unidos aprovou uma série de medidas duras para reforçar a segurança 
fronteiriça. ${ }^{11}$ Dentre as ações, mecanismos que facilitam a coleta de dados sobre as pessoas e organizações, bem como a partilha de informação sobre suspeitos de terrorismo. Neste sentido, foi ampliado o poder do governo para deter e deportar imigrantes. Migrar do México para os Estados Unidos ficou ainda mais difícil. Uma política cultural para a imigração/migração nestas condições é um desafio. E não se trata de um desafio apenas nos EUA. O fenômeno tem amplitude bem maior e escalas globais.

Se as políticas precisam levar em conta os grupos humanos, organizações sociais e agentes do estado relacionados com o ato de migrar, os grupos humanos em movimento migratório continuam a existir como um problema. E como mudar percepções em uma situação de medo generalizado do outro? $O$ acesso oferecido ao mundo pelas mídias digitais dá possibilidades para ideia de flaneurs do mundo. E o recado é triste: a liberdade de expressão não é uma realidade comum a todas as sociedades e nem os direitos são observados de forma equânime na atualidade. Como lidar com ações que remetem a preconceitos como o vivido por grupos humanos (ciganos, guarani, cimbri), ${ }^{12}$ mas que são justificados neste mesmo medo? Ou ainda os brasileiros em Boston, tal quais os "magrebines" em Paris, ou os jamaicanos em Londres, dividem experiências que produzem uma ambiência cultural privilegiada para observar modos de ação solidários, bem como ações de inclusão e ressignificações culturais vividas por esses grupos. Muitas histórias de encontros culturais que mais enriquecem do que amedrontam.

Pensar políticas de cultura para os migrantes no Brasil exige levar em conta que se trata de um país continental, portanto com fluxos migratórios internos importantes na constituição das fronteiras do país. Além do mais, desde o século XIX recebe imigrantes de todas as partes do planeta, dado que merece uma atenção especial. 
Desde os gaúchos na fronteira da Amazônia que migraram no pós-Segunda Guerra, como os nordestinos em todo o sudeste, notadamente em São Paulo, ou as inúmeras configurações regionais com seus polos atrativos na indústria, serviços ou agricultura. A migração interna no país segue, além da necessidade de mão de obra, os imperativos de ocupação estratégica do território. A necessidade de braços para os complexos da agroindústria do sudeste movimentaram milhares de pessoas do interior de Minas Gerais, e de estados do nordeste, para o sudeste na segunda metade do século XX, analisadas por Novaes e Alves (2007).

Muito antes disso, na ocupação estratégica do território no Brasil Colônia, ocorreu a migração interna como um imperativo categórico do Império Português, intensificados no século XVIII, com a imigração de açorianos e insulares. Contudo, foi a partir da constituição de 1824, após a independência, que alguns processos de significação do território foram produzidos. Um deles está relacionado à definição do cidadão brasileiro e da soberania. ${ }^{13}$ Foi neste período que ocorreu a opção pela imigração europeia para o Brasil. A partir do século XIX a pauta de estratégias de ocupação do território optou pela venda de lotes a imigrantes. Foram integrados ao sistema agrário do sudeste como mão de obra, como proprietários de terras no sul e como mão de obra da incipiente indústria em áreas urbanas. Neste sentido, está relacionada ao contexto das transformações socioeconômicas ocorridas com a Revolução Industrial. Os ânimos para a imigração foram arrefecidos com as convulsões em todo território no Período Regencial ${ }^{14}$ (PESAVENTO, 2009), mesmo que não tenha sido interrompida a ocupação do solo no Brasil.

A intensificação ou retomada da imigração no sul do país, coincide com a proibição formal do tráfico de escravos e a lei de terras, ${ }^{15}$ que davam o fermento necessário para tratar dos assentamentos 
dirigidos à ocupação de terras devolutas. Este projeto de ocupação do solo foi dirigido primeiramente ao Sul, depois São Paulo, que recebeu os maiores contingentes de imigrantes, Rio de Janeiro e Minas Gerais. As estatísticas pouco confiáveis nos dão apenas uma ideia do significado desse movimento. Algumas indicações afirmam que mais de cinco milhões de indivíduos teriam migrado para o Brasil até meados dos anos 1950. A maioria entre 18701920. Coincide com a primeira fase de caracterização geral do povo brasileiro. Este dado coloca, desde já, a questão de como estes grupos lidaram com a questão da assimilação. Ideia cara principalmente no Período Republicano.

Num sentido mais amplo, é o período de expansão máxima do imperialismo econômico inglês, do imperialismo cultural francês e alemão. Ao estudar este período, Dante Moreira Leite (1983) fez a denúncia dos modos de pensar de grupos de intelectuais, que a partir de seu lugar de classe, produziram e propalaram estereótipos sobre o caráter nacional brasileiro. As tentativas de definição foram reinventadas pelo modernismo, e ganharam feições de política pública de estado na Era Vargas.

Durante o período compreendido a partir de 1937 (Estado Novo) se vê uma franca campanha de modernização do país com fortes componentes nacionalistas. Tal campanha dirigida aos imigrantes atingia também todas as diferenças internas. O modernismo brasileiro e o debate em torno da raça no Brasil pendiam para a constatação da existência de um "candinho de raças" ou uma mestiçagem social e cultural. Isto não significa que as noções de pertencimento marcadas pela etnicidade não existissem. Exemplo disso são manifestações e embates simbólicos em festejos populares. Lugar ritualizado, a festa é palco de uma luta travada no campo simbólico. A produção de festas religiosas está relacionada ao tempo do sagrado e costumam congregar comunidades em torno de sua realização. 
Os migrantes portam suas heranças culturais. Idioma e religião formam um binômio importante na identidade de quem migra. Híbridas por definição, estas composições organizam a vida social dos indivíduos e grupos. Estes últimos, expostos a um mercado de bens simbólicos em transformação acelerada por conta, entre outras coisas, dos meios de comunicação de massa.

A era Vargas comportou um sentido nacionalizante, materializado pelas políticas para educação e para a saúde, que incluiu imensas regiões do Brasil, mas também promoveu o silenciamento das diferenças que pudessem enfraquecer o elemento nacional. Um exemplo pode ser observado nas ações da Frente Negra Brasileira, ${ }^{16}$ nas suas reivindicações civis e sociais. Para além da participação das festas populares, como o carnaval desde o século XIX, a falta de políticas públicas definidas para a educação, para a saúde, e a posse da terra da população livre e de ex-escravos eram evidentes. Tanto o carnaval, como as congadas e as festas populares, foram palco de reivindicação, se levarmos em conta as narrativas que engatam pertencimento em um grau atuante nas denúncias das políticas excludentes. Da mesma forma, as associações teuto-brasileiras, ou as entidades nipo-brasileiras foram também alvo da nacionalização. Nada poderia estar acima das referências nacionais.

Mas o que era este nacional que estava sendo reivindicado? A ideia de caldeamento que norteava as ações, não permite a presença de um Brasil das diferenças. Imperava o nacional, composto das partes, assimiladas por bem ou por mal na amálgama da moderna nação mestiça. Neste sentido, vale conferir a explicação da antropóloga Giralda Seyferth (1998, p. 223-237) sobre os processos de nacionalização vividos pelos imigrantes e outros grupos étnicos no Brasil: 
A assimilação forçada teve como inspiração a idéia de melting pot, expressão que, nos Estados Unidos se referia a americanização dos imigrantes europeus, o que não significava, necessariamente, abandono das identidades étnicas. No Brasil tornou-se sinônimo de caldeamento ou miscigenação e da possibilidade de incorporação dos imigrantes e seus descendentes a uma cultura brasileira de raízes portuguesas matizadas por elementos das culturas indígenas e africanas. Implícita nessa formulação estava a dificuldade de aceitar as diferenças de natureza étnica, o pluralismo e mesmo a heterogeneidade cultural. Mais do que não reconhecer a existência das minorias - como assinalou Willems ${ }^{17}$ em 1951 - os nacionalismos têm dificuldades de reconhecer como legítimas as identidades étnicas, mesmo de cidadãos exemplares, e as formas culturais produzidas pelas migrações e outros processos sociais. As culturas dos outros são quase sempre reduzidas à incômoda posição de anacronismos condenados pela modernidade.

Neste cenário, os projetos assimilacionistas norteavam as ações e o planejamento do que viria a ser a campanha de nacionalização, noção próxima da formulação de branqueamento na formação brasileira. Um conceito de "democracia racial" que circulava também entre os meios intelectuais nos anos 1930/50.

Tratar o tema de maneira abrangente remete a pensar os aspectos da liberdade de ação no ato da migração. Sayad (1998), ao estudar a imigração argelina para a França, nos apresenta o que ele define ser um processo total, na verdade as reflexões devem levar em conta desde os motivos da imigração até os componentes de adaptação e vida, bem como das possibilidades de retorno. Ou seja, migrar produz efeito no lugar de partida, no lugar de chegada, e cria-se um novo horizonte, a possibilidade de retorno. Impõe-se um recorte que traga luz para reflexões do tempo presente e os limites disso. Poderemos começar afirmando que os movimentos 
migratórios sendo tão antigos como a humanidade, nos leva à conclusão de que falar de migrações é falar da própria história da humanidade.

São os movimentos migratórios que constituem os atos de troca, da evolução tecnológica, da difusão de conhecimentos. Eles são constitutivos de um certo caminho da alteridade. Migrar é sair de algum lugar, mas é também seguir para outro. Encontros e desencontros. O mito de Caim e Abel, ${ }^{18}$ base de inúmeras narrativas que confrontam o pastor nômade e o agricultor territorializado, presentes nas formas de ver e descrever o ato de migrar e territorializar há muito tempo.

Retomando a questão da imigração no Brasil, devemos levar em conta as tradições que limitam o avanço sobre os direitos à diferença no campo da cultura. Estamos de acordo com o texto Políticas Culturais no Brasil: tristes tradições, enormes desafios, do professor Albino Rubim (2007), que indica as lacunas de ações transformadoras, participativas e mais duradouras no âmbito cultural brasileiro. As aproximações do conceito ampliado de cultura a partir da ideia da diversidade cultural apresentam a necessidade do planejamento estratégico de políticas culturais, bem como a necessidade de se levar em conta experiências de participação em conselhos de cultura. Essas práticas participativas de gestão cultural podem dar outro sentido para os processos de ressignificação das populações que migraram. (LUCENA; BARROS, 2010) $O$ texto apresenta a importância de ver a diversidade cultural em sua tríplice dimensão, uma referente às diferenças, enquanto realidade antropológica; da diversidade, enquanto resultado das interações e das trocas; e, enfim, enquanto pluralidade, como construção política da equidade. Neste sentido, vale lembrar o papel da Unesco na promoção da diversidade nestes cenários de encontros culturais promovidos pela migração. 
No caso brasileiro, foi a partir da constituição de 1988 que se inaugurou uma nova página da democracia brasileira. Inúmeros são os pontos que podem ser abordados a partir desta constatação. Iremos nos ater ao ocorrido na última década marcada por ações que tornam complexa a noção de democracia. As pré-conferências e conferências por todo o país preconizaram um momento ímpar para a participação social no alinhavo das políticas públicas nos diversos setores de atuação do estado brasileiro. (LUCENA; BARROS, 2010) A condução de eventos dessa magnitude exigiu uma organização para dar conta da amplitude de um país como o Brasil, levando em conta os setores participantes de cada um dos encontros e seus temas relativos. Afora os problemas pontuais, dos exageros e dos percalços na movimentação de milhares de pessoas e demandas, o saldo foi de uma participação efetiva naquilo que poderíamos chamar de gestão participativa das políticas públicas para a cultura no Brasil.

Para quem achar que isso é pouco, vale lembrar que o país tem uma herança autoritária, advinda das estruturas oligárquicas e escravocratas que sobreviveram ao fim do Império e suas mazelas. Mesmo na República, vamos encontrar práticas e discursos referentes à velha e rançosa observação de que as camadas populares incomodam mais do que contribuem nos processos decisórios. O esforço na superação de práticas autoritárias exige compromisso com ações inclusivas nos processos decisórios, lembrando da natureza mutante das práticas e dos discursos.

E aqui aparece uma primeira característica, ou uma virtude, dos participantes deste processo de gestão participativa da cultura: a paciência. Paciência para lidar com as diferenças, tão ricas neste país marcado pela imigração/migração como fato social constitutivo das identidades, mas também pela desigualdade de classes, por matrizes autoritárias nas relações de gênero, pela escravidão e 
suas heranças históricas. Configuração política difícil foi marcada por esforços de esvaziamento sistemático das pré-conferências e conferências, motivadas pelos setores pouco interessados em mudanças que alterem as zonas de conforto ocupadas há muito tempo. Ou ainda pelas dificuldades de locomoção próprias das variedades territoriais do Brasil. Virtude que mostrou os seus resultados: a maior participação popular da história da história da república brasileira em termos relativos e absolutos. Vamos nos lembrar que no Império e por boa parte da República, a população não participava diretamente das escolhas e das decisões importantes do país. Quadro que os movimentos sociais foram conquistando a duras penas ao longo da história do Brasil com sucessos nem sempre duradouros. (PESAVENTO, 2009) A segunda característica ou virtude emana de um passo mais efetivo na direção da democracia: a prudência. A prudência para não confiar nos velhos moldes da política no Brasil, feita por representantes desconectados do lugar social que dizem representar, mas bem afinados com os interesses que representam. Os povos indígenas, as mulheres, os homossexuais, os grupos que reivindicam a afrodescendência, as populações ribeirinhas, os migrantes de todos os rincões, falaram por si. Política trazida para a participação de cada um como cidadão, independente de sua origem étnica, da posição social, do credo religioso, da opção sexual, de origem territorial. Não deixar outros falarem por nós foi um dos pontos positivos das conferências e pré-conferências que ocorreram em praticamente todo o território nacional em pelo menos uma de suas modalidades - educação, cultura, água e meio ambiente, trânsito, cidades, infância e adolescência, igualdade racial, segurança pública, para dar alguns exemplos. (CALABRE, 2010)

Por fim, a terceira característica ou virtude desses encontros da cidadania foi a persistência, para compreender que muitas vezes 
é preciso bater várias vezes numa mesma porta. Mas bater com as próprias mãos e com toda a dignidade que as reivindicações exigem. O que em outros tempos era caso de polícia, punido com repressão aos seus atores, virou força política na mesa em que todos os jogadores tinham o mesmo peso. Ao menos lutaram para se fazer ouvir sem medo de verem suas reivindicações silenciadas. É muito cedo para medir os resultados de toda essa mobilização e deste movimento participativo tendo como horizonte as virtudes que emanaram deste momento histórico. (RUBIM, 2010) As mesmas forças que se fizeram presentes (ou se ausentaram de forma proposital, como na Conferência da Comunicação) podem ficar esperando para retomar espaços e posições. Neste sentido, a paciência, a prudência e a persistência cultivadas pelos atores sociais, parecem mostrar, como Marx sugere, que "tudo que é sólido, desmancha no ar". Ou mais precisamente, tudo, inclusive nossas formas de viver e de pensar são históricas. São, portanto, marcadas pelas nossas escolhas, como horizonte de possibilidades.

\section{Notas}

${ }^{1}$ Mito medieval de um lugar da fartura inesgotável. Foi retratado por Pieter Brueghel, o Velho (pintor flamengo; c. 1520/30-1569). O País da Cocagna (1567).

${ }^{2}$ Ocorrida há 9800 anos a. C.

${ }^{3}$ Segundo Georges Benko (1996) o processo de mundialização poderia ser visto em um apanhado de conjunto divido em três etapas. A primeira, a internacionalização, que está ligada ao desenvolvimento dos fluxos de exportação. A segunda, a transnacionalização, que liga-se aos fluxos de investimentos e das implantações no estrangeiro. A terceira fase, ou globalização corresponde à instalação das sedes mundiais de produção e de informação.

${ }^{4}$ A situação de penúria no campo empurrou camponeses à emigração, a fome e a miséria estavam presentes, costumando atormentar nos primeiros anos de algumas ou várias gerações após a imigração, como se pode verificar em 
comunidades de imigrantes oriundos da Itália e da Alemanha. (Cf. ALVIN, 1998, p. 215-287) Sobre as condições de vida na Itália no século XIX e os fatores geradores da emigração conferir Franzina (1976). Para a situação no Brasil, ver também Grandi (2001).

${ }^{5}$ Sobre estas preocupações conferir Delle Donne (1998).

${ }^{6}$ Faço uma discussão mais detida sobre isto em minha tese. (SEVERINO, 2004)

${ }^{7}$ Exemplo de preocupação com o tema é o trabalho de Oliveira (2006). Uma análise crítica das fronteiras da imigração no território brasileiro é desenvolvida por Martins (1997).

${ }^{8}$ Vale lembrar de "medo líquido", proposta por (BAUMAN, 2008), ou como em roteiros de filmes apocalípticos: O medo destrói... O livro Janela de Overton, do jornalista Glenn Back é uma narrativa que se enquadra nesta lógica do medo e da teoria da conspiração internacional.

${ }^{9} \mathrm{O}$ tema é recorrente na literatura e no cinema sobre as conspirações para o controle da população por corporações da informação e da segurança. Determinadas situações suprimem direitos em nome da segurança coletiva, fazendo a janela deslocar-se para menos ou para mais direitos, mas incorporadas ao cotidiano de forma naturalizada pelos cidadãos.

${ }^{10}$ UNESCO (1995). Cabe lembrar os direitos básicos da declaração de 1948 e do Pacto sobre os direitos econômicos, sociais e culturais de 1966: Direito ao lazer; direito à educação, direito à participação na vida cultural e científica; e direito à proteção dos interesses morais e materiais dos autores. (BATISTA, 2010)

${ }^{11}$ Sobre isso conferir Rosenblum (2011).

${ }^{12}$ Pequena comunidade de origem germânica que habita a região de Bolzano, no Norte da Itália (Trentino Alto-Adige).

${ }^{13} \mathrm{~A}$ constituição de 1824 estabelece os critérios que definem o cidadão, bem como os eleitores e elegíveis. Ainda no sentido de ordenamento, submete as províncias ao poder centralizador império. As tensões advindas disso podem ser observadas nas reivindicações de autonomia ou mesmo de independência em algumas províncias, como na Revolta dos Cabanos, na Revolução Farroupilha e na Sabinada. (PESAVENTO, 2009)

${ }^{14} \mathrm{~A}$ conturbada era regencial pode ser vista como o laboratório da nação, segundo Basile (2009). Entre as principais disputas na arena de lutas do período estão: Revolução do 7 de abril, 1831, na Corte; Mata-Marotos, 1831, na Bahia; Revolta do povo e da tropa, 1831, na Corte; Revolta do povo e da tropa, 1831, Pará; Setembrada, 1831, Maranhão; Setembrada, 1831, Pernambuco; Distúrbios do teatro, 1831, na Corte; Levante da Ilha das Cobras, na Corte, 1931; Novembrada, 1831, Pernambuco; Revolta de Pinto Medeira e Benze-cacetes, 1831-1832, no Ceará; Levantes federalistas (seis), 1831-1833, Bahia; Sedição de 
Miguel de Frias e Vasconcelos, 1832, na Corte; Sedição do Rio Negro, 1832, Pará; Revolta do Barão de Bülow, 1832, na corte; Abrilada, 1832, Pernambuco; Assuadas (duas), 1832, na Corte; Cabanada, 1832-1835, Pernambuco e Alagoas; Revolta do Ano da Fumaça, 1833, Minas Gerais; Carrancas, 1833, Minas Gerais; Revolta do povo e da Tropa, 1833, Pará; Conspiração do Paço, 1833, na Corte; Rusga Cuiabana, 1834, Mato Grosso; Carneiradas, 1834-1835, Pernambuco; Malês, 1835, Bahia; Cabanagem, 1835-1840, Pará; Revolução Farroupilha, 1835-1845, Rio Grande do Sul e Santa Catarina; Sabinada, 1837-1838, Bahia; Rebelião de Manuel Congo, 1838, Rio de Janeiro; Balaiada, 1838-1841, Maranhão e Piauí.

${ }^{15}$ Lei no 601 , de 18 de setembro de 1850 que estabeleceu as regras de acesso à terra.

${ }^{16}$ A Frente Negra Brasileira, fundada em 16 de setembro de 1931, funcionou até 1937. Foi a mais importante entidade de afrodescendentes na primeira metade do século XX.

${ }^{17} \mathrm{~A}$ autora se refere ao artigo de Willems (1951). De forma mais ampla o tema foi abordado em Willems (1946).

${ }^{18}$ Em Gênesis, Cap 4, vers., 1-24. Caim era pastor de ovelhas e seu irmão Abel era agricultor. Segundo o mito, as atenções de Deus para com Abel trouxeram a ira a Caim, que o matou. Ao marcar a terra com sangue de seu irmão, seu castigo deveria ser o de vagar pelo mundo com os seus descendentes e com uma marca que o protegeria. No Mito, este ato teria gerado os povos nômades, os músicos e os que trabalham com instrumentos de bronze e ferro.

\section{Referências}

ALVIN, Zuleika. Imigrantes: a vida privada dos pobres do campo. In: SE-VCENKO, Nicolau. (Org.) História da vida privada no Brasil: República da Belle Èpoque à era do rádio. São Paulo: Cia das Letras, 1998. p. 215-287.

ANDERSON, Perry. Internacionalismo: um breviário. Revista Anos 90, Porto Alegre, v. 12, n. 21/22, p.13-42, jan./dez. 2005.

BAUMAN, Z. Medo líquido. Rio de Janeiro: Jorge Zahar, 2008.

BATISTA, Vanessa Oliveira. O problema da efetivação dos direitos culturais. In; CALABRE, Lia. (Org.). Políticas culturais: diálogos e tendências. Rio de Janeiro: Ed. Casa de Rui Barbosa, 2010.

BENKO, Georges. Economia, espaço e globalização na aurora do século XXI. Tradução Antônio de Pádua Danesi. São Paulo: Hucitec, 1996.

BERLIN, Isaiah. Idéias políticas na era romântica: ascensão e influência no pensamento moderno. São Paulo: Cia das Letras, 2009. 
CALABRE, Lia. Políticas culturais no Brasil: história e contemporaneidade. Fortaleza: Banco do nordeste do Brasil, 2010.

CASTELLS, Manuel. O poder da identidade. 2. ed. São Paulo: Paz e Terra, 2000. (A era da informação: economia, sociedade e cultura; v. 2)

CERTEAU, Michel de. A escrita da história. Rio de Janeiro: Forense Universitária, 1982.

CHNAIDERMAN, Miriam. Racismo, o estranhamente familiar: uma abordagem psicanalítica. In: SCHWARCZ, Lilia Moritz; QUEIROZ, Renato da Silva (Org.) Raça e diversidade. São Paulo: Edusp: Estação Ciência, 1996.

DAMATTA, Roberto. Carnavais, malandros e heróis: para uma sociologia do dilema brasileiro. 4. ed. Rio de Janeiro: Zahar, 1983.

DELLE DONNE, Marcella (Org.). Relazioni etniche: stereotipi e pregiudizi: fenomeno immigratorio ed esclusione sociale. Roma: EdUP, 1998.

FEATHERSTONE, Mike (Org.). Cultura global: nacionalismo, globalização e modernidade. Petrópolis, RJ: Vozes, 1994.

FRANZINA, Emílio. La grande emigrazione. L'esodo dei rurali dal Veneto durante il secolo XIX. Venezia: Marsílio Editori, 1976.

FURTER, Reto; HEAD-König, Anne-Lise; LORENZETTI, Luigi. (Org.)

Les Migrations de retour. Zurich: Chronos Verlag, 2009.

GÊNESIS. Português. In: Bíblia Sagrada. Tradução CNBB. 10. ed. São

Paulo: Canção Nova, 2008. Capítulo 4, versículos 1-24.

GRANDI, Casimira. Storia di ordinaria emigrazione. Un approccio critico al flusso verso Santa Catarina. Estratto da Studi Trentini in Scienze

Storiche, Trento, Annata LXXX, sez I, n. 3, p. 487-496, 2001.

HALL, Stuart. A identidade cultural na pós-modernidade. São Paulo: DP\&A Editora, 2003.

HERDER, J. G. Ideias para a filosofia da história da humanidade. In:

GARDINER, Patrick. Teorias da história. Fundação Calouste Gulbenkian: Lisboa, 1995. p. 41-59.

HOBSBAWM. E. J. Nações e nacionalismo desde 1780: programa, mito e realidade. Rio de Janeiro: Paz e Terra, 1991.

JAMESON, Fredric. O inconsciente político. A narrativa como ato socialmente simbólico. Tradução Valter Lellis Siqueira. Revisão Maria Elisa Cevasco. São Paulo: Ática, 1992.

LEITE, Dante Moreira. O caráter nacional brasieliro. 4. ed. São Paulo: Pioneira, 1983.

LOBO, Eulália Maria Lahmeyer. Imigração portuguesa no Brasil. São Paulo: Hucitec, 2001. 
LUCENA, Giselle; BARROS, José Márcio. Diversidade cultural e conselhos de cultura: uma aproximação conceitual e empírica. In: RUBIM, Antonio Albino Canela et al. Políticas culturais, democracia e conselhos de cultura. Salvador: EDUFBA, 2010.

MARTINS, José de Souza. Fronteira: a degradação do outro nos confins do humano. São Paulo: Hucitec, 1997.

NOVAES, José Roberto; ALVES, Francisco (Org.) Migrantes: trabalho e trabalhadores no complexo agroindustrial canavieiro. São Carlos: EdUFSCar, 2007.

OLIVEIRA, Lucia Lippi. Nós e eles: relações culturais entre brasileiros e imigrantes. Rio de Janeiro: FGV, 2006.

PESAVENTO, Sandra Jatahy. Uma certa Revolução farroupilha. In:

GRIMBERG, Keilla; SALLES, Ricardo.(Org.) O Brasil Imperial. 1831-1870.

Rio de Janeiro: Ed. Civilização brasileira, 2009. (v. 2)

RAFFAINI, Patricia Tavares. Esculpindo a cultura na forma Brasil. São Paulo: Humanitas, 2001.

RIBEIRO, Darcy. O povo brasileiro: a formação e o sentido do Brasil. São Paulo: Companhia das Letras, 1995.

ROSENBLUM, Marc. R. US Immigration policy since 9/11. Migration Policy Institute: Washigton DC, 2011. Disponível em: <www.migrationpolicy. org. > Acesso em: 03 fev. 2012.

RUBIM, Antonio Albino Canelas; BARBALHO, Alexandre (Org.). Políticas culturais no Brasil. Salvador: EDUFBA, 2007.

RUBIM, Antonio Albino Canelas et al. Políticas culturais, democracia e conselhos de cultura. Salvador: EDUFBA, 2010.

SAYAD, Abdelmalek. Imigração ou os paradoxos da alteridade. São Paulo: Edusp, 1998.

SENNET, Richard. Carne e pedra: o corpo e a cidade na civilização ocidental. Rio de Janeiro: Record, 1997.

SEVERINO, J. R. Noi Oriundi: cultura, identidade e representações da imigração italiana em Santa Catarina. 2004. (Doutorado em História) Programa de História Social da Faculdade de Filosofia, Ciências Humanas e Letras da Universidade de São Paulo, Universidade de São Paulo, São Paulo, 2004.

SEYFERTH, Giralda. Algumas considerações sobre identidades étnicas e racismo no Brasil in VELHO, Gilberto. (Org.). Revista de cultura brasileña, Madrid, n. 1, p. 223-237. 1998.

SCHWARCZ, Lilia Moritz, Renato da Silva Queiroz (Org.) Raça e diversidade. São Paulo: Edusp: Estação Ciência, 1996. 
UNESCO, The migration information source. 1995. Disponível em: <www. migrationinformation.org >. Acesso em: 07 fev. 2012

WILLEMS, Emilio. Immigrants and their assimilitaion in Brazil. In: SMITH, T.L.; MARCHANT, A.(Ed.) Brazil. Portrait of half a continent. New York: Dryden Press, 1951.

. A aculturação dos alemães no Brasil. São Paulo: Cia Editora Nacional, 1946.

182 Políticas culturais e migraçōes 